\section{Physical activity, health-related quality of life and depression during pregnancy}

\author{
Atividade física, qualidade de vida e depressão \\ durante a gravidez
}

\footnotetext{
1 Escola de Psicologia, Universidade do Minho, Braga, Portugal.

2 Faculdade de Desporto Universidade do Porto, Porto, Portugal.

3 Universidade Portucalense

Porto, Portugal.

Correspondence

I. Tendais

Escola de Psicologia

Universidade do Minho.

Campus de Gualtar, Braga

4700-320, Portugal.

ivatendais@gmail.com
}

\begin{abstract}
This study examines physical activity patterns among women, from pre-pregnancy to the second trimester of pregnancy, and the relationship between physical activity status based on physical activity guidelines and health-related quality of life (HRQoL) and depression over pregnancy. 56 healthy pregnant women self-reported physical activity, HRQoL and depression at 10-15 and 19-24 weeks of pregnancy and physical activity before pregnancy. Whereas vigorous leisure physical activity decreased after conception, moderate leisure physical activity and work related physical activity remained stable over time. The prevalence of recommended physical activity was $39.3 \%$ and $12.5 \%$ in the 1 st and 2 nd trimesters of pregnancy respectively, and $14.3 \%$ pre-pregnancy. From the 1st to the 2 nd pregnancy trimester, most physical HRQoL dimensions scores decreased and only mental component increased, independently of physical activity status. No changes in mean depression scores were observed. These data suggest that physical activity patterns change with pregnancy and that physical and mental components are differentially affected by pregnancy course, independently of physical activity status.
\end{abstract}

Motor Activity; Quality of Life; Depression; Pregnancy
Iva Tendais 1

Bárbara Figueiredo 1

Jorge Mota 2

Ana Conde 3

\section{Introduction}

Regular physical activity throughout one's life span is recommended to promote and maintain good health and prevent premature mortality 1 . Moreover, an active lifestyle/exercise has been associated with more positive mood states, reduced risk of depression 2,3 and better healthrelated quality of life (HRQoL) in the general population 4,5 .

Unlike other periods, not all types of physical activity performed during pregnancy seem to be associated with health benefits. Several studies suggest leisure physical activity may have beneficial effects on maternal health by reducing the risk of gestational diabetes mellitus, preeclampsia, preterm birth and preventing excessive maternal weight gain during pregnancy $6,7,8,9$. Nevertheless, other studies either failed to demonstrate important benefits or risks 10 or documented adverse effects of exercise in pregnancy to the mother or fetus ${ }^{11}$. The intensity and time period of pregnancy in which the activity is performed, previous exercise history, dietary carbohydrate intake or maternal availability of oxygen seem to be important variables to take into account. High-intensity occupational activity and high demanding physical tasks at work (e.g. long hours of work, prolonged standing, lifting loads, night hours, irregular or shift-work schedules and high psychological demands) have been associated with adverse pregnancy outcomes 12,13,14. 
Studies of physical activity patterns during pregnancy show a low prevalence of recommended activity levels $15,16,17$, as well as a decline of leisure physical activity/sports/exercise and occupational activity across gestation $6,15,16,18,19,20,21,22,23,24$. Even so, there is some evidence that household and childcare activities are maintained over the course of pregnancy 18,22 or increase in the third trimester 23 . Recent studies suggest that transportation activity is also stable over pregnancy 15,25. A significant proportion of women may still perform strenuous physical activity during late pregnancy 26 . Thus, pregnancy seems to have a differential impact on physical activity intensity and modes. A shift from high to light intensity physical activity throughout pregnancy is observed $15,18,19,27$, as well as an energy economy in occupational and leisure activities 18 .

Pregnancy also seems to be a vulnerable time for depression 28 and lower HRQoL 29,30,31,32,33 when compared with other periods of life. Pregnant women report lower levels of physical functioning, vitality, social functioning and more limitations due to emotional problems than nonpregnant women ${ }^{33}$. Several studies also suggest that women demonstrate significant declines in physical functioning throughout pregnancy $29,31,34$.

Reduced well-being during pregnancy has also been associated with lower levels of physical activity 27,29. Pregnant women who exercise during the first and second trimesters of pregnancy report significantly less depressed mood, stateanxiety and pregnancy-specific stress compared with non-exercisers 27 and enhanced mood after exercise when compared with a parent-craft intervention or a control group 35. Lack of exercise prior to and during pregnancy has also been associated with poor or fair self-rated health and poor physical functioning during pregnancy 29 .

Surprisingly, little is known about the relationship between meeting physical activity guidelines before and during pregnancy and perceived HRQoL and depression during pregnancy. To address this gap, this study examines physical activity patterns of women from pre-pregnancy to the second trimester of pregnancy, and the relationship between physical activity status based on physical activity guidelines and HRQoL and depression changes over pregnancy.

\section{Method}

\section{Study design and population}

A longitudinal survey to assess physical activity, health-related quality of life and depression was carried out among healthy pregnant women in their first or second pregnancy trimesters who were attending one of four private obstetric clinics in Porto, Portugal. Previous consent was obtained from the private practice physicians specializing in obstetrics and gynaecology to recruit participants from their offices. From 1 May to 30 September 2005, pregnant women with singleton pregnancies, with 10-15 weeks of pregnancy and aged 18-40 years were invited to participate in the study. Women were not eligible if they had one of the following exclusion criteria: were not able to read and/or write Portuguese; had severe mental illness that seriously compromised mental functioning; had an obstetric, physical disease or adverse health condition that restricted habitual physical activity.

\section{Data collection}

Women volunteering for this study received from their attending physician at 10-15 weeks of pregnancy a detailed cover letter, an informed consent form and the questionnaires assessing socio-demographic and medical history, physical activity 3 months pre-pregnancy and at 1015 weeks of pregnancy, HRQoL and depressive symptoms in the first trimester of pregnancy. At 19-24 weeks, participants were asked to complete the same questionnaires with the exception of the socio-demographic and medical history questionnaire. The socio-demographic and medical history information collected included age, education level, marital status, number of pregnancies and children, employment status, previous diagnosed mental disorders, substance consumption (coffee, tobacco, alcohol and illicit drugs) prior to and during the first trimester of pregnancy, planning and initial acceptance of the current pregnancy.

Women were asked to return the questionnaires of both assessments in the same day of the medical appointment or in the next medical appointment. Missing information on the questionnaires was completed by phone when possible. Varying response rates were therefore observed in individual questions.

Of the 100 potentially eligible women that were approached, 78 agreed to participate in the study $(78 \%)$. Nine women were excluded either due to obstetric problems that limited normal physical activity $(n=4)$ or questionnaire fulfilment before or after 10-15 weeks and 19-24 weeks of pregnancy $(n=5) .69$ eligible participants completed the first assessment and 56 also the second $(72.7 \%)$. For the present analyses, participants included women who completed both assessments. Women who completed only the first 
assessment had similar demographic characteristics (age, education level), physical activity level at baseline and general health and depression at 10-15 weeks of pregnancy compared to women who completed both assessments.

The study protocol complied with the ethical principles contained in the Helsinki Declaration and was approved by the Scientific Committee of the Faculty of Medicine at the University of Porto and participants gave written informed consent to participate in the study.

HRQoL was assessed with the 36-Item ShortForm Health Survey (SF-36) 36, a generic measure designed to assess the individual perception of health status. The 36 items are grouped in to eight scales - physical functioning, role-physical, bodily pain, general health, vitality, social functioning, role-emotional, mental health - and two summary measures - physical component and mental component. Scores for each scale and component range from 0 to 100 , a higher value indicates a higher level of function. The SF-36 has been found to be a reliable and valid measure of health-related quality of life and used to study the relationship between exercise or physical activity and quality of life 4,29 . The SF-36 has been used and validated in Portugal 37,38,39.

Physical activity data was collected by the Global Physical Activity Questionnaire (GPAQ), a self-report measure with 18 items, derived from a previously validated questionnaire (International Physical Activity Questionnaire - IPAQ) 40. Frequency and time spent in physical activities of moderate- and vigorous-intensity for at least 10 minutes within the domains of work (household and occupational), transportation, and leisuretime physical activity during a typical week are assessed.

Women were classified as active or low active pre-pregnancy based on the American College of Sports Medicine (ACSM) and the American Heart Association (AHA) guidelines ${ }^{1}$ and during pregnancy based on the American College of $\mathrm{Ob}$ stetrics and Gynaecologists (ACOG) guidelines ${ }^{41}$. ACSM/AHA recommends that adults participate in 30 minutes or more of moderate-intensity aerobic physical activity during five days of the week or vigorous-intensity aerobic physical activity for at least 20 minutes, three days per week. Combinations of moderate- and vigorous-intensity physical activity can also be made to meet this recommendation 1. Metabolic equivalents (METs) are used to measure the amount of activity performed. When moderate- and vigorousintensity physical activity was reported a total physical activity index in weekly METs was calculated by summing the weighted frequency of moderate and vigorous activity using the follow- ing formula: (3-6 METs x moderate) $+(>6$ METs $\mathrm{x}$ vigorous) 42 . To meet the current recommendations of physical activity, the minimum value per week is 450 METs ( 30 min $\times 5$ days $\times 3$ METs $=450$ MET.min/week). During pregnancy, the ACOG limits the recommendation to moderate exercise during 30 minutes or more on most, if not all, days of the week in the absence of either medical or obstetric complications 41 .

Women reporting 150 minutes of moderate physical activity per week, 60 minutes of vigorous physical activity or at least 450 METs of combined moderate and vigorous physical activity pre-pregnancy and also 150 minutes of exercise per week during pregnancy were categorized as active and those who reported no activity or less than the recommended level per week were categorized as low active. Based on this classification, women were divided into four groups for analysis: low active both at pre-pregnancy and at 10-15 weeks of pregnancy, low active pre-pregnancy and active at 10-15 weeks of pregnancy, active both at pre-pregnancy and at 10-15 weeks of pregnancy, active pre-pregnancy and low active at 10-15 weeks of pregnancy.

Depression was assessed using the Edinburgh Postnatal Depression Scale (EPDS) 43. This questionnaire is a self-report measure of depression symptoms consisting of 10 items scored on a 4-point likert scale (0-3) with 0 indicating absence of depressed mood and 3 the worst mood within the previous seven days. Higher scores indicate increasing severity of depressive symptoms. EPDS has been used in several countries, including Portugal, during pregnancy and the postpartum period 44,45 . A score equal to or higher than 10 is suggestive of the presence of clinical depression 44 . The Portuguese version of EPDS 46 showed good reliability (Cronbach alpha $=0.85$, test-retest $\mathrm{r}=0.75)$ and validity $(\mathrm{r}=0.86$ with the Schedule for Affective Disorders Psychiatric Interview).

\section{Statistical analysis}

Changes over time regarding the proportions of physical activity modes and intensities, as well as the prevalence of recommended physical activity throughout the study period were investigated by means of Cochran's Q test, which tests for differences between three or more matched sets of proportions. McNemar 2 related sample tests were used for post hoc comparisons between pairs of time points (1st vs. 2nd, 2nd vs. $3^{\text {rd, }} 1^{\text {st }}$ vs. 3rd). A Bonferroni correction was used to adjust for the number of tests and so the effects are reported at 0.017 level of significance.

Repeated-measures analysis of variance was carried out to determine changes in modes and 
intensities of physical activity over time. Pairwise comparisons were made and the Bonferroni correction was applied. Similar analyses were performed to test for differences between active and low active groups in HRQoL dimensions and depression scores during pregnancy. GreenhouseGeisser estimates are reported when the sphericity assumption was violated. Mean difference $(\Delta)$ between the two pregnancy trimesters (2nd minus 1st) was calculated to analyze how variables changed over time. A positive $\Delta$ indicates an increase in HRQoL dimensions or depression scores, whereas a negative $\Delta$ indicates a decrease in these scores over pregnancy. Extreme values were excluded to prevent an undesirable influence on the mean values. When significant between-subject effects were found, one-way analysis of variance was used to test for group differences at each pregnancy trimester.

Data were analyzed using SPSS version 17 (SPSS Inc., Chicago, USA) and a p-value $<0.05$ was considered significant.

\section{Results}

The sociodemographic characteristics of the sample are summarized in Table 1. The mean age was 30.4 years ( $\mathrm{SD}=4.0$, range $20-39$ years). More than half had college education (62.5\%),

Table 1

Sociodemographic characteristics of study sample $(n=56)$.

\begin{tabular}{|c|c|c|}
\hline Characteristics & $\mathrm{n}$ & $\%$ \\
\hline \multicolumn{3}{|l|}{ Age (years) } \\
\hline $20-26$ & 7 & 12.5 \\
\hline $27-33$ & 36 & 64.3 \\
\hline $34-39$ & 13 & 23.2 \\
\hline \multicolumn{3}{|l|}{ Education (years) } \\
\hline$<10$ & 13 & 23.2 \\
\hline $10-12$ & 8 & 14.3 \\
\hline$>12$ & 35 & 62.5 \\
\hline \multicolumn{3}{|l|}{ Marital status } \\
\hline Married/Cohabitate & 53 & 94.6 \\
\hline Single/Divorced & 3 & 5.4 \\
\hline \multicolumn{3}{|l|}{ Employment status } \\
\hline Employed & 52 & 92.9 \\
\hline Student/Other & 4 & 7.1 \\
\hline \multicolumn{3}{|c|}{ Number of previous pregnancies } \\
\hline 0 & 34 & 60.7 \\
\hline 1 & 16 & 28.6 \\
\hline$\geq 2$ & 6 & 10.7 \\
\hline
\end{tabular}

and were primiparous (60.7\%). The majority was married or cohabiting (94.6\%) and was employed at the time of enrolment (92.9\%). Approximately $11 \%$ reported smoking and $8.9 \%$ drinking alcohol before pregnancy and $5.4 \%$ reported smoking at 10-15 weeks of pregnancy. There was no self-reported use of illicit drugs. At the first and second assessment, pregnant women had an average of 12.2 and 21.3 weeks of gestation, respectively.

\section{Physical activity from pre-pregnancy to the second trimester of pregnancy}

Longitudinal changes in physical activity modes and intensities are displayed in Table 2 .

No significant changes in moderate leisure physical activity proportions $[\mathrm{Q}(2)=4.17$, $\mathrm{p}=0.124]$ were observed from pre-pregnancy to 19-24 weeks of pregnancy, as well as in moderate $[\mathrm{Q}(2)=2.00, \mathrm{p}=0.368]$, vigorous $[\mathrm{Q}(2)=4.00$, $\mathrm{p}=0.135]$ and total work physical activity $[\mathrm{Q}(2)=3.00, \mathrm{p}=0.223]$. Transportation physical activity was reported by approximately one quarter of women and remained also fairly stable over the same period $[\mathrm{Q}(2)=0.118, \mathrm{p}=0.943]$. In contrast, vigorous $[\mathrm{Q}(2)=18.20, \mathrm{p}<0.001]$ and total $[\mathrm{Q}(2)=8.09, \mathrm{p}=0.018$ ) leisure physical activity proportions changed significantly (Table 2). Vigorous leisure physical activity proportion declined from pre-pregnancy to 10-15 weeks (McNemar $\mathrm{p}=0.004$ ) and to 19 -24 weeks of pregnancy $($ McNemar $\mathrm{p}=0.002)$. Total leisure physical activity proportion declined from pre-pregnancy to $10-15$ weeks (McNemar $\mathrm{p}>0.017 ; \mathrm{n}=56$ ) and to $19-24$ weeks of pregnancy (McNemar $\mathrm{p}>0.017$; $n=56$ ), although these declines were not statistically significant.

The time spent in moderate $[\mathrm{F}(1.71,94.14)=$ $0.26, \mathrm{p}=0.735]$, vigorous $[\mathrm{F}(1.55,55.0)=1.73, \mathrm{p}=$ $0.194]$, total work physical activity $[\mathrm{F}(1.56,85.63)$ $=0.61, \mathrm{p}=0.507]$, moderate leisure physical activity $[\mathrm{F}(2,49)=2.97, \mathrm{p}=0.061]$ and transportation $[\mathrm{F}(1.62,85.67)=0.21, \mathrm{p}=0.763]$, did not change significantly between the three time points, whereas vigorous $[\mathrm{F}(1.09,57.80)=6.68, \mathrm{p}=0.011]$ and total leisure physical activity $[\mathrm{F}(1.54,76.94)=$ $7.89, \mathrm{p}=0.002$ ] changed over time (Table 2). Before pregnancy, women engaged in more vigorous and total leisure physical activity compared to the first $(\mathrm{p}=0.019)$ and second $(\mathrm{p}=0.008)$ pregnancy trimesters. No significant differences were observed between the two pregnancy trimesters for these intensities.

\section{Prevalence of recommended activity}

The prevalence of women who reached the recommended level of physical activity pre-preg- 
Modes, frequency and intensity of self-reported physical activity (min/week) before and at the first two trimesters of pregnancy.

\begin{tabular}{|c|c|c|c|c|c|c|c|}
\hline & \multicolumn{2}{|c|}{ Pre-pregnancy } & \multicolumn{2}{|c|}{ 10-15 weeks of pregnancy } & \multicolumn{2}{|c|}{ 19-24 weeks of pregnancy } & \multirow[t]{2}{*}{ p-value * } \\
\hline & $\%$ & Mean (SD) & $\%$ & Mean (SD) & $\%$ & Mean (SD) & \\
\hline \multicolumn{8}{|l|}{ Leisure activity } \\
\hline Moderate & 42.4 & $48.4(74.1)$ & 35.7 & $39.8(67.0)$ & 28.6 & $22.5(48.6)$ & 0.061 \\
\hline Vigorous & 22.2 & $41.1(105.8)$ & 5.4 & $6.1(28.2)$ & 3.6 & $3.1(17.6)$ & 0.011 \\
\hline Total *夫 & 48.2 & 72.5 (103.8) & 35.7 & $39.8(71.7)$ & 28.6 & $25.9(54.0)$ & 0.002 \\
\hline \multicolumn{8}{|l|}{ Work activity } \\
\hline Moderate & 12.5 & $165.2(706.0)$ & 10.7 & $154.2(669.0)$ & 7.1 & $128.6(563.7)$ & 0.735 \\
\hline Vigorous & 3.6 & $27.3(155.3)$ & 0.0 & 0 & 0.0 & 0 & 0.194 \\
\hline Total ** & 14.3 & $192.5(745.6)$ & 10.7 & $154.2(669.0)$ & 7.1 & $128.9(563.6)$ & 0.507 \\
\hline Transportation activity & 27.3 & $75.10(19.05)$ & 27.3 & $64.17(17.40)$ & 29.1 & $71.02(23.43)$ & 0.763 \\
\hline
\end{tabular}

* $\mathrm{p}$-value form the mean difference between the three time points using repeated measures analysis of variance;

** Total physical activity is the sum of moderate and vigorous physical activity.

nancy proposed by the ACSM/AHA was $39.3 \%$. During pregnancy, the proportion was $12.5 \%$ and $14.3 \%$ in the first and second trimester respectively, based on the ACOG recommendation. This represents a significant change on recommended physical activity over time $[\mathrm{Q}(2)=21.10$, $\mathrm{p}<0.001$ ]. The proportion declined significantly from pre-pregnancy to $10-15$ weeks (McNemar $\mathrm{p}$ $<0.001$ ) and to 19-24 weeks (McNemar p = 0.001), but not between pregnancy trimesters (McNe$\operatorname{mar} \mathrm{p}=1.00$ ).

Women meeting the recommended levels of physical activity both before pregnancy and during the first trimester of pregnancy represented $12.5 \%$, whereas $26.8 \%$ that were previously active became low active at 10-15 weeks of pregnancy and $60.7 \%$ remained low active during these two time periods.

Health-related quality of life, depression and recommended physical activity

Table 3 shows the mean (SD) scores on the HRQoL and depression measures at each trimester of pregnancy according to physical activity status. Overall, substantial changes in health status during pregnancy were observed, mainly in HRQoL physical dimensions. While the physical component $[\mathrm{F}(1,48)=32.7, \mathrm{p}<0.001]$, physical functioning $[\mathrm{F}(1,49)=32.0, \mathrm{p}<0.001]$, role-physical $[\mathrm{F}(1,49)=8.7, \mathrm{p}=0.05]$ and general health $[\mathrm{F}(1,51)=63.3, \mathrm{p}<0.001]$ mean scores declined significantly from the first to the second trimester of pregnancy, the mental component $[\mathrm{F}(1,48)=$ $13.8, \mathrm{p}=0.001]$ mean scores increased independently of physical activity status. The mean bodily pain $[\mathrm{F}(1,50)=3.2, \mathrm{p}=0.079]$, vitality
$[\mathrm{F}(1,50)=0.45, \mathrm{p}=0.504]$, social functioning $[\mathrm{F}(1,52)=1.6, \mathrm{p}=0.218]$, role-emotional $[\mathrm{F}(1,52)=$ $1.7, \mathrm{p}=0.199]$ and mental health $[\mathrm{F}(1,46)=0.04$, $\mathrm{p}=0.836$ ] scores did not meaningfully change from early to mid pregnancy. Significant group differences were noted in mental health $[\mathrm{F}(2,46)=$ $4.06, \mathrm{p}=0.024]$ mean scores. Low active women before and during the first trimester of pregnancy had higher mental health at 19-24 weeks than active women that became low active at 10-15 weeks of pregnancy $(p=0.015)$.

Mean depression scores were stable at both trimesters of pregnancy $[\mathrm{F}(1,43)=0.06, \mathrm{p}=0.814]$. No significant group differences were found in depression scores according to physical activity status $[\mathrm{F}(2,43)=1.89, \mathrm{p}=0.164]$.

\section{Discussion}

The purpose of this study was to examine the physical activity patterns of women from prepregnancy to the second trimester of pregnancy, and the relationship between physical activity status based on physical activity guidelines and HRQoL and depression changes over pregnancy.

Our results are generally consistent with previous research indicating a significant decline in time spent in total $16,19,20$ and vigorous leisure physical activity and stable levels of moderate leisure physical activity from pre-pregnancy to pregnancy 6,19. Similarly, Haakstad et al. 6 have also documented a higher proportion of women with vigorous leisure physical activity pre-pregnancy compared to the first and second trimesters of pregnancy. No changes on leisure time physical activity were observed from the first 
Health-related quality of life and the first two trimesters of pregnancy according to physical activity status both before and at the first trimester.

\begin{tabular}{|c|c|c|c|c|c|c|c|c|}
\hline & \multicolumn{2}{|c|}{$\begin{array}{l}\text { Low active pre-pregnancy } \\
\text { and at } 10-15 \text { weeks of } \\
\text { pregnancy }(n=34)\end{array}$} & \multicolumn{2}{|c|}{$\begin{array}{l}\text { Active pre-pregnancy and } \\
\text { low active at } 10-15 \text { weeks } \\
\text { of pregnancy }(n=15)\end{array}$} & \multicolumn{2}{|c|}{$\begin{array}{c}\text { Active pre-pregnancy and at } \\
10-15 \text { weeks of } \\
\text { pregnancy }(n=7)\end{array}$} & \multicolumn{2}{|c|}{$\Delta=2$ nd -1 st trimester } \\
\hline & $\begin{array}{c}\text { 1st trimester } \\
\text { Mean (SD) }\end{array}$ & $\begin{array}{c}2^{\text {nd }} \text { trimester } \\
\text { Mean (SD) }\end{array}$ & $\begin{array}{l}\text { 1st trimester } \\
\text { Mean (SD) }\end{array}$ & $\begin{array}{c}2^{\text {nd }} \text { trimester } \\
\text { Mean (SD) }\end{array}$ & $\begin{array}{c}\text { 1st trimester } \\
\text { Mean (SD) }\end{array}$ & $\begin{array}{c}\text { 2nd trimester }^{\text {Mean (SD) }} \\
\text { Mea }\end{array}$ & $\begin{array}{c}\text { Mean } \\
\text { difference } \\
(95 \% \mathrm{Cl})\end{array}$ & $\mathrm{p}$-value * \\
\hline \multicolumn{9}{|l|}{ SF-36 } \\
\hline Physical component & $82.3(10.6)$ & $72.1(14.8)$ & $80.2(13.7)$ & $64.5(17.2)$ & $90.4(2.1)$ & $72.3(14.0)$ & $-14.7(-19.8 ;-9.5)$ & $<0.001$ \\
\hline Physical functioning & $86.3(9.2)$ & $75.0(14.9)$ & $84.3(9.8)$ & $67.1(14.1)$ & $86.7(9.3)$ & $72.5(21.6)$ & $-14.2(-19.2 ;-9.1)$ & $<0.001$ \\
\hline Role-physical & $86.9(15.3)$ & $84.8(17.3)$ & $82.7(11.2)$ & $67.8(20.5)$ & $90.2(12.9)$ & $81.3(13.5)$ & $-8.7(-14.5 ;-2.8)$ & 0.005 \\
\hline Bodily pain & $82.5(18.5)$ & $78.5(21.0)$ & $73.3(23.1)$ & $71.9(24.1)$ & $100.0(0.0)$ & $87.2(18.0)$ & $-6.0(-12.8 ; 0.7)$ & 0.079 \\
\hline General health & $81.3(13.3)$ & $69.8(6.7)$ & $80.3(14.0)$ & $66.7(6.7)$ & $92.6(7.5)$ & $73.1(3.5)$ & $-14.8(-18.5 ;-11.1)$ & $<0.001$ \\
\hline Mental component & $64.3(13.3)$ & $72.5(12.0)$ & $59.6(21.5)$ & $65.7(19.8)$ & $66.9(11.7)$ & $79.5(11.0)$ & $9.0(4.1 ; 13.8)$ & 0.001 \\
\hline Vitality & $55.7(18.0)$ & $60.0(15.0)$ & $52.7(15.8)$ & $54.9(16.5)$ & $68.8(16.5)$ & $67.9(12.7)$ & $1.9(-3.7 ; 7.5)$ & 0.504 \\
\hline Social functioning & $87.1(15.5)$ & $86.7(15.0)$ & $80.0(16.9)$ & $79.2(18.7)$ & $80.4(9.8)$ & $92.9(9.8)$ & $3.8(-2.3 ; 9.8)$ & 0.218 \\
\hline Role-emotional & $88.4(15.6)$ & $88.4(16.7)$ & $87.2(19.1)$ & $81.7(20.0)$ & $94.0(10.4)$ & $88.1(11.6)$ & $-3.8(-9.8 ; 2.1)$ & 0.199 \\
\hline Mental health & $78.6(11.0)$ & $83.0(9.7)$ & $70.0(23.9)$ & $68.3(24.7)$ & $87.5(6.1)$ & $83.3(11.3)$ & $-0.5(-4.9 ; 3.9)$ & 0.836 \\
\hline \multicolumn{9}{|l|}{ Depression } \\
\hline EPDS & $4.5(2.7)$ & $3.9(2.4)$ & $5.9(5.0)$ & $6.3(4.5)$ & $3.8(2.6)$ & $3.7(2.3)$ & $0.1(-0.8 ; 1.1)$ & 0.814 \\
\hline
\end{tabular}

$\Delta$ : mean difference; EPDS: Edinburgh Postnatal Depression Scale; SF-36: 36-Item Short-Form Health Survey.

* $\mathrm{p}$-value for the mean difference between the three time points from repeated measures analysis of variance.

to the second trimester of pregnancy. This was not an unexpected finding as major changes in leisure physical activity have been noted when comparing the beginning and middle gestation with the end period of gestation 6,15,18,19,25,27.

In terms of work physical activity, we found no significant time differences or proportions during the studied period. In our study, work physical activity includes both paid and nonpaid work physical activity and it is not possible to know if the lack of variance in this measure is due to a simultaneous decrease on paid work activity and an increase on non-paid work activity. Schmidt et al. 23 observed that household/caregiving activity energy expenditure was higher in late pregnancy, whereas occupational physical was lower in the third trimester compared to the first trimester. Other studies 18,21 reported that household activity remained unchanged throughout pregnancy.

The reported time spent in total leisure physical activity and work physical activity before and during pregnancy was markedly lower than in previous studies 15,47 . One possible explanation for this discrepancy with the literature is that only moderate and vigorous intensity activities were assessed. In our study, women spent, on average, 1 hour in leisure physical activity and little more than 3 hours in work physical activity before pregnancy, 40 minutes in leisure time physical activity and 2h30min in work physical activity at the first trimester and less than $30 \mathrm{~min}$ utes in leisure time physical activity and 2 hours in work physical activity per week at the second trimester of pregnancy. Previous studies have documented that first-time mothers and women who do not participate in moderate or vigorous physical activity before pregnancy seem to feel unsafe/unsure about vigorous physical activity during pregnancy 48 . As most pregnant women in our study were primiparous and had low levels of vigorous physical activity before pregnancy it is possible that they felt more reluctant to perform high intensity activities, especially when only moderate physical activity is currently recommended. Health professionals may have an important contribution to the adoption of a more active lifestyle during pregnancy, especially in previously sedentary women. According to the ACOG guidelines 41 , previously sedentary women should be evaluated before recommendations for physical activity are made. In addition, more than half of our sample have white-collar occupations (data not shown) and, thus, report very 
low levels of work physical activity, especially of a vigorous intensity. It is possible, however, that job adaptations have been made in some cases since a decrease in moderate work physical activity is observed from prepregancy to the second trimester of pregnancy, although these differences were not statistically significant. Job adjustment in pregnancy is foreseen in European legislation 49 .

A somewhat higher proportion of participation in transportation physical activity was obtained (27\% before pregnancy and in the first trimester, $29 \%$ in the second trimester), as well as a greater amount of time spent per week in this activity compared with previous studies 15,25. However, a similar pattern of stability during pregnancy was observed.

Consistent with the literature, a decreasing prevalence of recommended leisure physical activity was found from pre-pregnancy to pregnancy. Evenson et al. 17 found a lower prevalence of recommended physical activity among pregnant compared with non-pregnant women (15.8\% vs. 26.1\%) and Hausenblas \& Downs 19 reported a linear decrease in exercise from pre-pregnancy to the third trimester of pregnancy $(38.5 \%$ before pregnancy, $17 \%$ at first trimester, $14.1 \%$ at second and $7.5 \%$ at third trimester of pregnancy). The 1988 National Maternal and Infant Health Survey data (USA) analyzed by Leiferman \& Evenson 9 and Zhang \& Savitz 24 revealed that $48 \%$ of the 9,089 women studied retrospectively reported exercising regularly (3 or more times per week) before pregnancy and $41 \%$ during pregnancy. According to the prospective study of 7,281 young women (aged 18-23 years) participating in the Australian Longitudinal Study of Women's Health, having a first or subsequent child increases the risk of not reaching the recommended level of physical activity 50 . The reported estimates of recommended activity during pregnancy varied from $3 \%$ to $78 \% 15,17,19,47$. Three factors may explain the wide array of estimates: (1) diverse definitions of active, (2) different time frames (e.g. activities before/after you found out you were pregnant, activities over the last seven days in the first, second and third trimesters of pregnancy and (3) diverse sample characteristics (race/ethnic background, employment status, education level, age). Our findings suggest that the decrease in the proportion of recommended activity after conception is mostly explained by the restriction on activity type and intensity in the definition of recommended activity. Overall, women maintain moderate levels of leisure physical activity during early to mid pregnancy.

Pregnant women reported more limitations in physical activities because of health problems, more problems with daily activities as a result of physical health and a more negative perception of their health based on physical limitations from the beginning to middle gestation, independently of physical activity status. The decline of physical functioning during pregnancy is supported by the findings of other studies 31,34 . The results of Haas et al. 29 suggest that women have increasing limitations in physical function during pregnancy when compared with pre-pregnancy. These authors compare physical functioning mean scores during pregnancy with studies of people with congestive heart failure, diabetes, and recent myocardial infarction. In contrast, an increase in the mental component was observed, as well as in most mental dimensions, although it was not statistically significant. Förger et al. 34 found stable mental health scores from pre-pregnancy to 24 weeks postpartum in healthy pregnant women, although no results were provided regarding physical and mental components.

Unexpectedly, women that became low active at 10-15 weeks of pregnancy reported lower mental health at the second trimester than women who continued to be low active in the first trimester of pregnancy. This result suggests that reduced leisure physical activity at the first trimester is associated with poor psychological well-being and higher distress during mid pregnancy in previously active women compared with women who were already low active before pregnancy. This decrement might be voluntary or forced by the appearance of physical discomforts associated with pregnancy that may inhibit leisure physical activity. Based on this finding, it is unclear whether women become low active due to decreased mental health or that the decrease in physical levels impairs their mental health. Even so, Poudevigne \& O'Connor 51 argue that a relationship between pregnancy-related reductions in physical activity and psychological distress is plausible, given the known links between inactivity and reduced mental health. Women who become low active in early pregnancy may perceive their mental health more negatively than inactive women probably because physical activity had previously been an important coping strategy to deal with stress and negative emotions, while inactive women used other coping strategies. Future research is needed to confirm this hypothesis.

\section{Study limitations and strengths}

Some limitations should be recognized. First, we used a questionnaire to analyze physical activity, which is an indirect method and involves a series of measurement difficulties that comes with such instruments. Nevertheless, while objective meth- 
ods have been developed such as accelerometers it will be hard to use them due to the sample characteristics. Further, the instrument (GPAQ) was validated against accelerometers. Second, the use of a highly educated convenience sample makes it difficult to make generalizations about the results obtained, and apply them to a wider population of women. Future studies are needed to confirm our results in larger and more diverse groups of pregnant women. Another limitation of our study was the small number of pregnant women included and the multiple comparisons made.

This study also demonstrates the importance of measuring other domains of physical activity than leisure physical activity 52 by revealing the amount of time women spent on paid and nonpaid work physical activity before and during pregnancy and its relation to well-being and depression. To our knowledge, this is the first study to examine the relationship between physical activity status before and during early pregnancy and HRQoL and depression.

In conclusion, pregnancy reduces vigorous leisure activity and the proportion of women engaging in recommended levels of physical activity. Physical HRQoL decreases from early to mid pregnancy independent of changes in physical activity, but not mental HRQoL. Although the depressive symptoms remain stable in all physical activity groups, women that become low active at early pregnancy experience impaired mental health. This information is helpful when counseling women to promote mental well-being and prevent the potential risk of mental health problems.

\section{Resumo}

Este estudo examina os padrões de atividade física antes da concepção até o segundo trimestre de gravidez e a relação entre o nível de atividade física, com base nas recomendações de atividade física, a qualidade de vida relacionada à saúde (QVRS) e depressão ao longo da gravidez. Cinquenta e seis grávidas saudáveis reportaram nível de atividade física, QVRS e depressão às 10-15 e 19-24 semanas de gravidez, além de atividade física antes da concepção. Enquanto a atividade física vigorosa no lazer diminuiu depois da concepção, as atividades físicas moderadas no lazer e no trabalho mantiveram-se estáveis. A prevalência de atividade física recomendada foi de 39,3\%, 12,5\% e 14,3\% antes, no primeiro e no segundo trimestres de gravidez, respectivamente. Independentemente do estatuto de atividade física, a maior parte dos escores nas dimensões físicas da QVRS diminui do primeiro para o segundo trimestre de gestação, e apenas o componente mental aumenta. Não se verificaram alterações nos escores médios de depressão. Estes dados sugerem que, com a gravidez, há alteração nos padrões de atividade física; além disso, os componentes físico e mental são diferentemente afetados pelo curso da gestação, independentemente do nível de atividade física.

Atividade Motora; Qualidade de Vida; Depressão; Gravidez

\section{Contributors}

I. Tendais carried out the research and wrote the article. B. Figueiredo and J. Mota provided orientation for the analysis, data interpretation, and reviewed the article. A. Conde contributed to the data analysis and reviewed the manuscript. 


\section{References}

1. Haskell WL, Lee IM, Pate RR, Powell KE, Blair SN Franklin BA, et al. Physical activity and public health: updated recommendation for adults from the American College of Sports Medicine and the American Heart Association. Med Sci Sports Exerc 2007; 39:1423-34.

2. Camacho T, Roberts R, Lazarus N, Kaplan G, Cohen R. Physical activity and depression: evidence from the Alameda County Study. Am J Epidemiol $1991 ; 134: 220-31$.

3. Fox KR. The influence of physical activity on mental well-being. Public Health Nutr 1999; 2:411-8.

4. Atlantis E, Chow C, Kirby A, Singh MF. An effective exercise-based intervention for improving mental health and quality of life measures: a randomized controlled trial. Prev Med 2004; 39:424-34.

5. Bize R, Johnson JA, Plotnikoff RC. Physical activity level and health-related quality of life in the general adult population: a systematic review. Prev Med 2007; 45:401-15.

6. Haakstad LA, Voldner N, Henriksen T, Bo K. Physical activity level and weight gain in a cohort of pregnant Norwegian women. Act Obstet Gynecol Scand 2007; 86:559-64.

7. Schlüssel MM, Souza EB, Reichenheim ME, Kac G. Physical activity during pregnancy and maternalchild health outcomes: a systematic literature review. Cad Saúde Pública 2008; 24 Suppl 4:S531-44.

8. Polley BA, Wing RR, Sims CJ. Randomized clinical trial to prevent excessive maternal weight gain in pregnant women. Int J Obes Relat Metab Disord 2002; 26:1494-502.

9. Leiferman JA, Evenson KR. The effect of regular leisure physical activity on birth outcomes. Matern Child Health J 2003; 7:59-64.

10. Kramer MS, McDonald SW. Aerobic exercise for women during pregnancy. Cochrane Database Syst Rev 2006; 3:CD000180.

11. Magann EF, Evans SF, Weitz B, Newham J. Antepartum, intrapartum, and neonatal significance of exercise on healthy low-risk pregnant working women. Obstet Gynecol 2002; 99:466-72.

12. Croteau A, Marcoux S, Brisson C. Work activity in pregnancy, preventive measures, and the risk of delivering a small-for-gestational-age infant. Am J Public Health 2006; 96:846-55.

13. El Metwalli AGA, Badawy AM, Baghdadi LA, El Wehady A. Occupational physical activity and pregnancy outcome. Eur J Obstet Gynecol Reprod Biol 2001; 100:41-5.

14. Hatch M, Ji BT, Shu XO, Susser M. Do standing, lifting, climbing, or long hours of work during pregnancy have an effect on fetal growth? Epidemiology 1997; 8:530-6.

15. Borodulin KM, Evenson KR, Wen F, Herring AH, Benson AM. Physical activity patterns during pregnancy. Med Sci Sports Exerc 2008; 40:1901-8.

16. Domingues MR, Barros AJ. Leisure-time physical activity during pregnancy in the 2004 Pelotas Birth Cohort Study. Rev Saúde Pública 2007; 41:173-80.

17. Evenson KR, Savitz DA, Huston SL. Leisure-time physical activity among pregnant women in the US. Paediatr Perinat Epidemiol 2004; 18:400-7.
18. Clarke P, Rousham E, Gross H, Halligan A, Bosio P. Activity patterns and time allocation during pregnancy: a longitudinal study of British women. Ann Hum Biol 2005; 32:247-58.

19. Hausenblas H, Downs D. Prospective examination of leisure-time exercise behavior during pregnancy. J Appl Sport Psychol 2005; 17:240-6.

20. Hinton PS, Olson CM. Predictors of pregnancyassociated change physical activity in a rural white population. Matern Child Health J 2001; 5:7-14.

21. Mottola MF, Campbell MK. Activity patterns during pregnancy. Can J Appl Physiol 2003; 28:642-53.

22. Poudevigne MS, O'Connor PJ. A review of physical activity patterns in pregnant women and their relationship to psychological health. Sports Med 2006; 36:19-38.

23. Schmidt MD, Pekow P, Freedson PS, Markenson G, Chasan-Taber L. Physical activity patterns during pregnancy in a diverse population of women. J Womens Health (Larchmt) 2006; 15:909-18.

24. Zhang J, Savitz DA. Exercise during pregnancy among U.S. women. Ann Epidemiol 1996; 6:53-9.

25. Evenson KR, Wen F. National trends in self-reported physical activity and sedentary behaviours among pregnant women: NHANES 1999-2006. Prev Med 2010; 50:123-8.

26. Fox NS, Gelber SE, Chasen ST. Physical and sexual activity during pregnancy and near delivery. J Womens Health (Larchmt) 2008; 17:1431-5.

27. Da Costa D, Rippen N, Dritsa M, Ring A. Self-reported leisure-time physical activity during pregnancy and relationship to psychological well-being. J Psychosom Obstet Gynaecol 2003; 24:111-9.

28. Gorman LL, O'Hara MW, Figueiredo B, Hayes S, Jacquemain F, Kammerer MH, et al. Adaptation of the structured clinical interview for DSM-IV disorders for assessing depression in women during pregnancy and post-partum across countries and cultures. Br J Psychiatry Suppl 2004; 46:S17-23.

29. Haas JS, Jackson RA, Fuentes-Afflick E, Stewart AL, Dean ML, Brawarski P, et al. Changes in the health status of women during and after pregnancy. J Gen Intern Med 2004; 20:45-51.

30. Haas JS, Meneses V, McCormick MC. Outcomes and health status of socially disadvantaged women during pregnancy. J Womens Health Gend Based Med 1999; 8:547-53.

31. Hueston WJ, Kasik-Miller S. Changes in functional health status during normal pregnancy. J Fam Pract 1998; 47:209-12.

32. McKee MD, Cunningham M, Jankowski KR, Zayas L. Health-related functional status in pregnancy: relationship to depression and social support in a multi-ethnic population. Obstet Gynecol 2001; 97:988-93.

33. Otchet F, Carey MS, Adam L. General health and psychological symptom status in pregnancy and the puerperium: what is normal? Obstet Gynecol 1999; 94:935-41.

34. Förger F, Østensen M, Schumacher A, Viliger PM. Impact of pregnancy on health related quality of life evaluated prospectively in pregnant women with rheumatic diseases by the SF-36 health survey. Ann Rheum Dis 2005; 64:1494-9. 
35. Polman R, Kaiseler M, Borkoles E. Effect of a single bout of exercise on the mood of pregnant women. J Sports Med Phys Fitness 2007; 47:103-11.

36. Ware Jr. JE, Sherbourne CD. The MOS 36-item short-form health survey (SF-36). I. Conceptual framework and item selection. Med Care 1992; 30:473-83.

37. Ferreira PL. Criação da versão portuguesa do MOS SF-36: parte I - adaptação cultural e linguística. Acta Med Port 2000; 13:55-66.

38. Ferreira PL. Criação da versão portuguesa do MOS SF-36: parte II - testes de validade. Acta Med Port 2000; 13:119-27.

39. Severo M, Santos AC, Lopes C, Barros H. Fiabilidade e validade dos conceitos teóricos das dimensões de saúde física e mental da versão portuguesa do MOS SF-36. Acta Med Port 2006; 19:281-7.

40. Craig CL, Marshall AL, Sjostrom M, Bauman AE, Booth ML, Ainsworth BE, et al. International physical activity questionnaire: 12-country reliability and validity. Med Sci Sports Exerc 2003; 35: 1381-95.

41. American College of Obstetricians and Gynecologists. Exercise during pregnancy and the postpartum period. Clin Obstet Gynecol 2003; 46:496-9.

42. Ainsworth BE, Haskell WL, Whitt MC, Irwin ML, Swartz AM, Strath SJ, et al. Compendium of physical activities: an update of activity codes and MET intensities. Med Sci Sports Exerc 2000; 32(9 Suppl):S498-504.

43. Cox J, Holden J, Sagovsky R. Detection of postnatal depression. Development of the 10-item Edinburgh Posnatal Depression Scale. Br J Psychol 1987; 150:782-6.

44. Areias M, Kumar R, Barros H, Figueiredo E. Comparative incidence of depression in women and men, during pregnancy and after childbirth. Validation of the Edinburgh Posnatal Depression Scale in Portuguese mothers. Br J Psychiatry 1996; 169:30-5.
45. Teixeira C, Figueiredo B, Conde A, Pacheco A, Costa R. Anxiety and depression during pregnancy in women and men. J Affect Disord 2009; 119:142-8.

46. Augusto A, Kumar R, Calheiros J, Matos E, Figueiredo E. Post-natal depression in an urban area of Portugal: comparison of childbearing women and matched controls. Psychol Med 1996; 26:135-41.

47. Pereira MA, Rifas-Shiman SL, Kleinman KP, RichEdwars JW, Peterson KE, Gillman MW. Predictors of change in physical activity during and after pregnancy: Project Viva. Am J Prev Med 2007; 32:312-9.

48. Mudd LM, Nechuta S, Pivarnik JM, Paneth N; Michigan Alliance for National Children's Study. Factors associated with women's perceptions of physical activity safety during pregnancy. Prev Med 2009; 49:194-9.

49. European Union. Council directive 92/85/EEC of on the introduction of measures to encourage improvements in the safety and health at work of pregnant workers and workers who have recently given birth or are breastfeeding. http:// eur-lex.europa.eu / LexUriServ/LexUriServ. do?uri=CELEX:31992L0085:EN:HTML (accessed on 24/Aug/2010).

50. Brown WJ, Trost SG. Life transitions and changing physical activity patterns in young women. Am J Prev Med 2003; 25:140-3.

51. Poudevigne MS, O'Connor PJ. Physical activity and mood during pregnancy. Med Sci Sports Exerc 2005; 37:1374-80.

52. Ainsworth BE. Challenges in measuring physical activity in women. Exerc Sport Sci Rev 2000; 28:93-6.

Submitted on $01 / \mathrm{Jul} / 2010$

Final version resubmitted on 21/Sep/2010

Approved on 13/Oct/2010 